\title{
Health Scope
}

\section{Health Promotion Thinking, Interpretation and Implementation in Iran: Capacities, and the Way Forward}

\author{
Nastaran Keshavarz ${ }^{1^{*}}$ \\ ${ }^{1}$ School of Public Health, Shahid Beheshti University of Medical Sciences, Tehran, Iran \\ *Corresponding author: Nastaran Keshavarz, School of Public Health, Shahid Beheshti University of Medical Sciences, Tehran, Iran. Tel: +98-9124153782, Fax: \\ +98-5412420014, E-mail: n_keshavars@yahoo.com
}

Keywords: Health Promotion; Iran

Reviewing the history of public health in the past 60 years indicates evidence of significant changes and adaptive developmental shifts in public health focuses and approaches to health. Our collective understanding about health and its determinants has changed from non-scientific approaches to the scientific approaches including medical, psychological, ecological, social and more recently systems approaches (1). The concept of "health promotion" coined in Ottawa Charter in 1986 (2), was a revolutionary shift from reductionist individualistic perspective to holistic population perspective to health which values the role of the context and its political, economic, environmental and social dimensions. The Ottawa charter advocates for five key actions including building healthy policies, creating supportive environments, strengthening community actions, developing individual skills and re-orienting health systems.

Since emergence of health promotion approach to health the required capacity for implementing health promotionvalues,principlesandconceptsweredeveloped in many countries Especially developed countries. Health promotion capacity can include essential knowledge, skills, commitment, structures, systems and leadership (3) policies, institutions, programs and practices (4) to enable effective health promotion and mainstreaming health promotion for strengthening national health systems and promote population health. However, these complementary and adaptive changes did not happen in all regions and countries in a similar ways. While the uptake of health promotion in developed countries led to significant change in their capacities such as policy, infrastructure and practice and hence improved their population health, many developing countries lagged behind. Although the dialogue of health promotion has been diffused in many developing countries such as Iran, the research shows differences in the understanding of key concepts of health promotion and lack of a functional health promotion infrastructure in the majority of developing countries around the world (5).

In case of Iran, for example, although in recent years the term "Health Promotion" is increasingly used in verbal and written communications and literature, but

-Article type: Editorial; Received: 01 Mar 2013, Revised: 07 Mar 2013, Accepted: 13 Mar 2013;

-Implication for health policy/practice/research/medical education:

This paper can contribute to diffusion and implementation of health promotion approach to health in health policy, health planning, health programs and reorienting health systems in Iran.

PPlease cite this paper as:

Health Promotion Thinking, Interpretation and Implementation in Iran: Capacities, and the Way Forward. Health Scope. 2013; 2(1): 1-3. DOI: $10.17795 /$ jhealthscope-10642 
rarely real academic meaning is understood. Often it is understood as "improving health" mainly by medical or health care and health advice. Medical approach to health is still the most dominant approach to understand health, obviously with longest history, while psychological approach to health known as "health education approach" has also 60 years history. It seems that we are at the edge of third public health revolution giving birth to social approach to health or "Health Promotion".

\section{Landscape of Health Promotion Changes in Iran}

It can be said the returning the first Iranian health promotion graduates from overseas in 1996 played an important role in introducing the health promotion concepts in Iran. Few years later the first health promotion committees were established within the Ministry of health. Furthermore, attendance of the time manager of health education office of the Ministry and few other senior managers of the health system in WHO Health Promotion Conference in Mexico in 2000, helped significantly to further diffusion of health promotion concepts in Iran. As a result, many educational activities for introducing the concepts of health promotion were implemented, such as translation and wide dissemination of global health promotion documents for instance Health Promotion Glossary in different levels of the health system. Many workshops were also held for health education officers across the country regarding the new concepts introduced by health promotion approach. The gradual shift in dialogue within the Ministry led to adding the term "Health Promotion" to the name of the Office of Health Education in 2009. This was followed by retitling the Health Education Board to Health Education and Promotion Board in 2010 and also similarly the name of health educational departments in schools of public health changed to "Health Education and Promotion Departments. Finally the name of the national health education association and its journal changed to health education and promotion in 2010. In 2012, the PhD degree of health education was replaced by a new curriculum of the "Health Education and Promotion" (6), hence many health promotion courses were developed for the first time within universities. In addition new research centers and journals under the label of health promotion were established in recent few years.

It should be noted that these changes reflect the acceptance of health promotion concept as a complement to health education, however these acceptance was not priceless, smooth and fast. At the beginning, there was a hesitance even rejection of the term by mainly health education experts as some saw that as treating to the old health education field. As the health promotion approach to health still has not been implemented in practice, yet little challenge has been perceived by medical professionals in top managerial and decision making positions.

\section{Superficial Uptake of Health Promotion Concepts}

Despite these changes due to strong dominance of medical approach to health in Iran, lack of true evidenceinformed practice, weak and superficial understanding of health promotion concepts, inadequate infrastructure and limited capacity of health promotion, health promotion perspectives has not been properly interpreted an or effectively implemented in Iran. For example, the current understanding of many stakeholders about health promotion is very limited, there is significant shortage of competent health promotion experts, researchers and officers and limited funding. As a result, still in national health policies, systems, planning and programs the most dominant approach to health is expensive medical approach. WHO seriously encourages the nations to improve the health of their nations through their ability to refocus health systems to include the promotion of health (7). With growing the number of health promotion experts in Iran and better communicational infrastructures and networking among health professional and establishment of health promotion courses, one can hope that health promotion approach is about to be implemented in managing the health challenges of 21 century.

\section{The Way Forward}

Learning from international experiences (8), it seems that capacity mapping followed by the capacity development for health promotion in Iran is among the first and most important steps to be taken. Key prerequisites of effective implementation of Health Promotion Approach are significant attention and effective actions to train component health promotion workforce, secure sustainable financing, and development of research and knowledge management infrastructures.

Similar to many other developed and developing countries, Non Communicable Disease (NCD) is a major issue of health system in Iran. WHO advocates for health promotion approach to health and diseases, especially to NCD (9-11), which its effectiveness has been approved. Hence, one of the important changes that all should help to happen in Iran is the shift from medical approach to health and disease to Health Promotion Approach especially among national policy makers and decision makers as well as public health professionals. It is hoped that this editorial will contribute to a critical and timely dialogue on the great need to health promotion thinking and interpretation in a way to inform evidence-informed and cost effective practice. 


\section{Acknowledgements}

None declared

\section{Authors' Contribution}

This study has one author.

\section{Financial Disclosure}

None declared.

\section{Funding/Support}

None declared.

\section{References}

1. Beaglehore R, Bonita R. Public Health at the Crossroads: Achievements and Prospects. Cambridge: Cambridge University Press. 1997

2. WHO . Ottawa Charter for Health Promotion. Ottawa. 1986;

3. Smith BJ, Tang KC, Nutbeam D. WHO Health Promotion Glossary: new terms. Health Promot Int. 2006;21(4):340-5
4. Mittelmark MB, Wise M, Nam EW, Santos-Burgoa C, Fosse E, Saan $\mathrm{H}$, et al. Mapping national capacity to engage in health promotion: overview of issues and approaches. Health Promot Int. 2006;21 Suppl 1:91-8

5. Hodgins M, Battel-Kirk B, Asgeirsdottir AG. Building capacity in workplace health promotion: the case of the Healthy Together e-learning project. Glob Health Promot. 2010;17(1):60-8

6. Deputy for Education. The national curriculum for PhD degree of Health Education and Promotion.The Ministry of Health, Iran. 2011

7. WHO . Health-Promoting Health Systems: Imperatives for Action. Nairobi, Kenya: 2009.Document prepared as a working document for discussion at the 7th Global Conference on Health Promotion, "Promoting Health and Development: Closing the Implementation Gap" Nairobi, Kenya.

8. HEALTH CANADA. Health promotion in Canada: a case study. Health Promotion International.1998;13(1)

9. Alwan Ala. The NCD Global Strategy Action Plan and NCDnet: Accelerating implementation through collective and coordinated action. 2010.

10. WHO . Assessing national capacity for the prevention and control of non-communicable diseases: report of the 2010 global survey. Geneva. 2012

11. WHO . Closing the gap: Policy into practice on social determinants of health. Geneva. 2011 